\title{
Residues Depletion Study and Withdrawal Period Determination of Sulphadiazine and Trimethoprim Premix in Pigs
}

\author{
${ }^{1}$ Athanasia Tzivara, ${ }^{1}$ Vassilis G. Papatsiros, ${ }^{2}$ Vassilis Katsoudas, \\ ${ }^{2}$ Lydia Dritsa, ${ }^{1}$ Panagiotis Dimitrios Katsoulos, ${ }^{2}$ Maria Evaggelidou, \\ ${ }^{2}$ Eftychia Aravidou and ${ }^{2}$ Georgios Christodoulopoulos \\ ${ }^{1}$ Department of Clinical Veterinary Medicine, \\ School of Veterinary Medicine, University of Thessaly, 43100, Greece \\ ${ }^{2}$ Provet S.A. G.L.P. Unit, Aspropyrgos, Attica, Greece
}

Received 2012-05-14, Revised 2012-07-02; Accepted 2013-04-12

\begin{abstract}
The emergence and spread of antibiotic resistant human pathogens have been directly linked to the use of antibiotics in livestock production. The purpose of this study was to detect and quantify the concentration of the residues of Sulphadiazine (SDZ) and Trimethoprim (TMP) in edible tissues of pigs and to determine the withdrawal period after oral administration of OPTIPRIME ${ }^{\circledR}$ premix $40 \%$, containing $66.7 \mathrm{~g}$ TMP and $333.3 \mathrm{~g}$ SDZ per kg to healthy pigs. The depletion profile of SDZ and TMP was studied in healthy pigs, after oral administration of $1.5 \mathrm{~kg}$ OPTIPRIME ${ }^{\circledR}$ per ton of feeding stuff, for 5 consecutive days. A total of 22 pigs at age $65 \pm 2$ days and from $27.1-33.0 \mathrm{~kg}$ were used. The experimental animals were divided into 4 groups (5 pigs per group), while 2 pigs acted as control animals. All medicated pigs were sacrificed 1, 4, 7 and 11 days after the last administration and muscle, fat, liver and kidney tissues were collected and analyzed using a validated liquid chromatography-mass spectrophotometry method. On the 1st day post medication (pm), SDZ was found in muscle and fat at higher concentrations than TMP, whereas higher concentrations of TMP were found in the liver, while both substances were found in high concentrations in kidney samples. On 4th day pm SDZ and TMP could not be quantified or detected in any tissue. On 7th day pm, both substances were found in quantifiable concentrations in 1 out of 4 kidney samples, while on 11th day pm, all observations were below the Limit of Quantification (LOQ) of the method. The results show that both substances deplete rapidly in all tissues. A withdrawal period of 5 days is justified for the commercial product OPTIPRIME ${ }^{\circledR} 40 \%$ premix in pigs.
\end{abstract}

Keywords: Higher Concentrations, Directly Linked, Antibiotic Resistant, Chromatography-Mass, Limit of Quantification (LOQ), Withdrawal Period, Residuals, Trimethoprim, Sulphadiazine, Pig

\section{INTRODUCTION}

Antimicrobial agents, such as antibiotics, have been used in pig production for over 50 years. Veterinary drug residue is one of many global issues concerning food safety (Schwarz and Chaslus-Dancla, 2001). In addition, the emergence and spread of antibiotic resistant human pathogens have been directly linked to the use of antibiotics in animal husbandry (EC, 1999; Randall et al., 2004; Pastor-Navarro et al., 2004; Akond et al., 2009). Low-level drug contamination of animal's feed is one causative channel of residues in animal products (McCaughey et al., 1990; Rokka et al., 2005).

Trimethoprim is known as a folic acid antagonist and is commonly used in combination with sulfonamides to treat gastrointestinal and respiratory tract infections in

Correspondence Author: Vassilis G. Papatsiros, Department of Clinical Veterinary Medicine, School of Veterinary Medicine, University of Thessaly, 43100, Greece Tel: 003024410-66012 Fax: 003024410-66053 
farm animals. Several pharmacokinetic studies on these two drugs have been performed on pigs after intravenous or oral administration (Luther, 1979; Lu, 1986; Friis et al., 1984a; 1984b). Sulfonamides are widely used for therapeutic and prophylactic purposes in pigs (Guise et al., 1986; Nielsen and Gyrd-Hansen, 1994; Schwarz and Chaslus-Dancla, 2001), sometimes as growth promoters or additives in animal feed (Long et al., 1990). At present, sulphonamides are one of the most common contaminating antimicrobials in animal feed, generating potentially serious problems in human health, such as allergic or toxic reactions or bacterial resistance (Schwarz and Chaslus-Dancla, 2001).

In order to protect consumers from risks related to drug residues, Maximum Residue Limits (MRL) have been established by legislation in many countries. In Europe, Canada and the USA, the MRL for the total sulphonamide concentrations in edible tissues is $100 \mu \mathrm{gkg}^{-1}$ (EC, 1999) and $20 \mu \mathrm{g} \mathrm{kg}^{-1}$ in Japan (Pastor-Navarro et al., 2004). Several methods for the determination of sulphonamides have been reported as High-Performance Liquid Chromatography (HPLC), liquid chromatography-mass spectrometry (LC/MS), Gas Chromatography (GC), ThinLayer Chromatography (TLC), High Performance Capillary Electrophoresis (HPCE), Enzyme-Linked Immunosorbent Assay (ELISA), Biosensor Immunoassay (BIA) and microbiological methods (Wang et al., 2006; Kandimalla et al., 2007; Pastor-Navarro et al., 2009).

It is important for public health that new methods for the detection of the withdrawal period of the most common antibiotics, such as Sulphadiazine (SDZ) and Trimethoprim (TMP) combinations in pigs, are extensively investigated. Withdrawal periods, ranging from a few days to a few weeks, are recommended for approved animal drugs. Failure to adhere to these recommended periods is reported to be the primary cause of violative levels of veterinary drugs in food (KuKanich et al., 2005). In the present study, due to consumers' concern about the use of antimicrobials in livestock animals, we investigated the residues and withdrawal period of SDZ and TMP combination in pigs, using very sensitive analytical methods. More specifically, the aim of this study was to detect and quantify the concentration of the residues of SDZ and TMP in edible tissues of pigs and to determine the withdrawal period after oral administration of OPTIPRIME ${ }^{\circledR}$ premix $40 \%$ to healthy pigs at the maximum recommended dosage.

\section{MATERIALS AND METHODS}

\subsection{Experimental Material}

A medicated premix (OPTIPRIME ${ }^{\circledR}$ premix 40\%) which contains $66.7 \mathrm{~g}$ Trimethoprim (TMP) and $333.3 \mathrm{~g}$ Sulphadiazine (SDZ) per $\mathrm{kg}$ was used in this study.
OPTIPRIME $^{\circledR}$ premix $40 \%$ is a white or off-white powder medicated premix, manufactured by PROVET S.A.

\subsection{Trial Farm}

The trial has been performed in a commercial all-in, all-out farrow-to-finish farm, used for educational purposes by the School of Veterinary Medicine, University of Thessaly (Clinical Veterinary Medicine Department), located in Karditsa, Greece.

\subsection{Experimental Animals}

Twenty two pigs (16 male and 6 female), commercial hybrids of the same genetic background ( $Q$ Landrace $\mathrm{x}$ LW / $\widehat{\sigma}$ Duroc) were used in this study at age $65 \pm 2$ days, upon arrival and with bodyweight (BW), upon arrival, from 27.1-33.0 $\mathrm{kg}$ The experimental animals were divided into four groups ( 5 pigs per group), while two pigs acted as control animals.

The animals were housed in 4 pens ( 5 animals per pen) and they were identified individually by ear tags. The control animals were also housed in a separated pen. Animal randomization was performed on the basis of bodyweight and similar group mean bodyweights were achieved. Special attention was paid to including animals of both genders in each group. The building had natural lighting and ventilation. To determine the environmental conditions, the maximum and minimum temperatures as well as the relative humidity were monitored and recorded at approximately the same time each day. During the study the temperature ranged between 7.9$33.1^{\circ} \mathrm{C}$. The relative humidity ranged between $20-76 \%$.

Each pen was equipped with a feeder. Animals were fed twice daily with a concentrated diet. Feed was given in quantities sufficient to cover nutritional requirements according to their age and performance. The animals had free access to water. Fresh water was available to all animals for ad libitum consumption throughout the study.

\subsection{Trial Design}

During the acclimatisation period of 7 days, the general clinical condition of the animals was checked by a veterinarian. All animals were weighed on day-7, on the day before the first and the fourth administration and within $24 \mathrm{~h}$ before sacrifice. These bodyweights were used for allocation to experimental groups and dose calculations, respectively.

OPTIPRIME $^{\circledR}$ premix $40 \%$ was orally administered following incorporation in animal feeding stuff to 20 out of 22 pigs, once daily for five consecutive days to animals of groups A, B, C, D at the maximum recommended dose of $1.5 \mathrm{~kg}$ OPTIPRIME ${ }^{\circledR}$ premix $40 \%$ per tone of feeding stuff (equivalent to $30 \mathrm{mg}$ of 
combined active ingredients per $\mathrm{kg} \mathrm{BW}$ or $3 \mathrm{~g}$ OPTIPRIME $^{\circledR}$ premix $40 \%$ per $\left.40 \mathrm{~kg} \mathrm{BW}\right)$. The other two animals (group M) were used in the study as control animals. During the whole study the animals were monitored for their general health condition. Feed consumption per pen was documented.

The medicated premix was incorporated into the feeding stuff according to EMEA/CVMP/036/95 (1996) and GMP Guidelines, in the GMP facility of PROVET S.A. in Aspropyrgos, with a mechanical mixer. According to the homogeneity and stability results the mixture (animal feedstuff and medicated premix) was found to be homogeneous and stable. The animals were weighed the day before the 1st and the 4th administration in order to calculate the quantity of the mixture (animal feedstuff and medicated premix) that should be administered to each group (consisted of 5 animals) during the morning feeding. The concentration of the mixture in OPTIPRIME ${ }^{\circledR}$ premix $40 \%$ was calculated in order to assure that the daily dose of the medicated premix was contained in a quantity of ration less than the half of the daily ration of the animals under treatment. At the procedure of this calculation, the number was rounded to the following number of the mathematically calculated 1 st decimal digit, due to possible spreading of the mixture during administration and consumption. Therefore, each group consumed $1.7 \mathrm{~kg}$ of the incorporated feed with the medicated premix during the first three administrations and $1.8 \mathrm{~kg}$ during the last two administrations. The next three hours after administration of the medicated feed, the animals were observed and any reluctance to feed consumption was recorded. At the time when all the animal groups had consumed the administrated quantity of the medicated mixture, the feeder was filled half of the quantity of the daily feed consumption.

\subsection{Records}

During the whole study the animals were monitored for general health condition. The animals were observed twice daily for clinical signs of irritation due to drug administration, toxicity, illness or behavioural abnormality. Furthermore, feed consumption per pen was documented twice daily.

To examine residue depletion one group per slaughter day was sacrificed at 1 (Group A), 4 (Group B), 7 (Group C) and 11 days (Group D) after the last administration. The untreated control animals (Group M) were sacrificed at the same day with the animals of group A (prior to their sacrifice). From all animals the following tissue samples were collected: muscle, fat, liver and kidneys. All samples were sent to the G.L.P. Analytical Laboratory and were analysed by means of a validated analytical method, described as "Determination of SDZ and TMP in tissues, using reversed phase liquid chromatography and MS detection".

Prior to sacrificing, written veterinary assessments were carried out by evaluating the daily food consumption and by clinically examining the animals. The decision whether the animals were suitable for slaughter was based on the outcome of those assessments. The sacrificed animals were also inspected post mortem. General inspection was made of the condition appearance of each carcass, presence of external parasites, condition of the skin, colouration of the skin and mucous membranes, presence of any wounds, lesions, malformations and abnormal fluid discharge.

A closer examination was then made on the individual organs and tissues, in particular the liver, kidneys, muscle and fat. The liver and kidneys were examined both on the outer surface and the interior/cut surface as appropriate. Just after sacrificing, the following tissues and organs were collected from each animal: muscle tissue (approximately $300 \mathrm{~g}$ ), fat (approximately $300 \mathrm{~g}$ ), both kidneys after removing their capsule and the liver (minus the gall bladder). After sacrificing, the remaining of all carcasses was removed and handed over for destruction at slaughterhouse "IASON S.A". A certificate for the removal and disposal of the animal waste was signed by the appropriate personnel. Each sample was weighed, double wrapped in plastic bags and labelled with a pre-typed label. The collected samples were sent directly in dry ice to the G.L.P. facilities of the company in Aspropyrgos, Attica.

\subsection{Analytical Methodology and Validation}

All the analytical work, including method development and validation was carried out at the analytical Laboratory of the PROVET S.A. GLP Test Unit. Limit of detection and limit of quantification for the antibiotic tested were appropriately calculated. The validated Limits of Quantification (LOQ) were: SDZ, 25.1 $\mu \mathrm{g} \mathrm{kg}^{-1}$ in all tissues and for TMP, $12.6 \mu \mathrm{g} \mathrm{kg}^{-1}$ in all tissues. The method describes the determination of concentrations of SDZ and TMP in animal tissues using reversed phase liquid chromatography and mass spectrometric detection.

According to the developed method, in $5 \mathrm{~g}$ tissue sample (cut into small pieces in the case of fat, kidney and liver samples or minced through a meat mincing machine for muscle samples), acetonitrile was added. The sample was homogenized and centrifuged. A portion of the supernatant was transferred to a clear 8 $\mathrm{mL}$ tube and evaporated to dryness with nitrogen. The residue was re-dissolved in final solvent followed by a clean-up step with hexane. 
Athanasia Tzivara et al. / American Journal of Animal and Veterinary Sciences 8 (1): 37-44, 2013

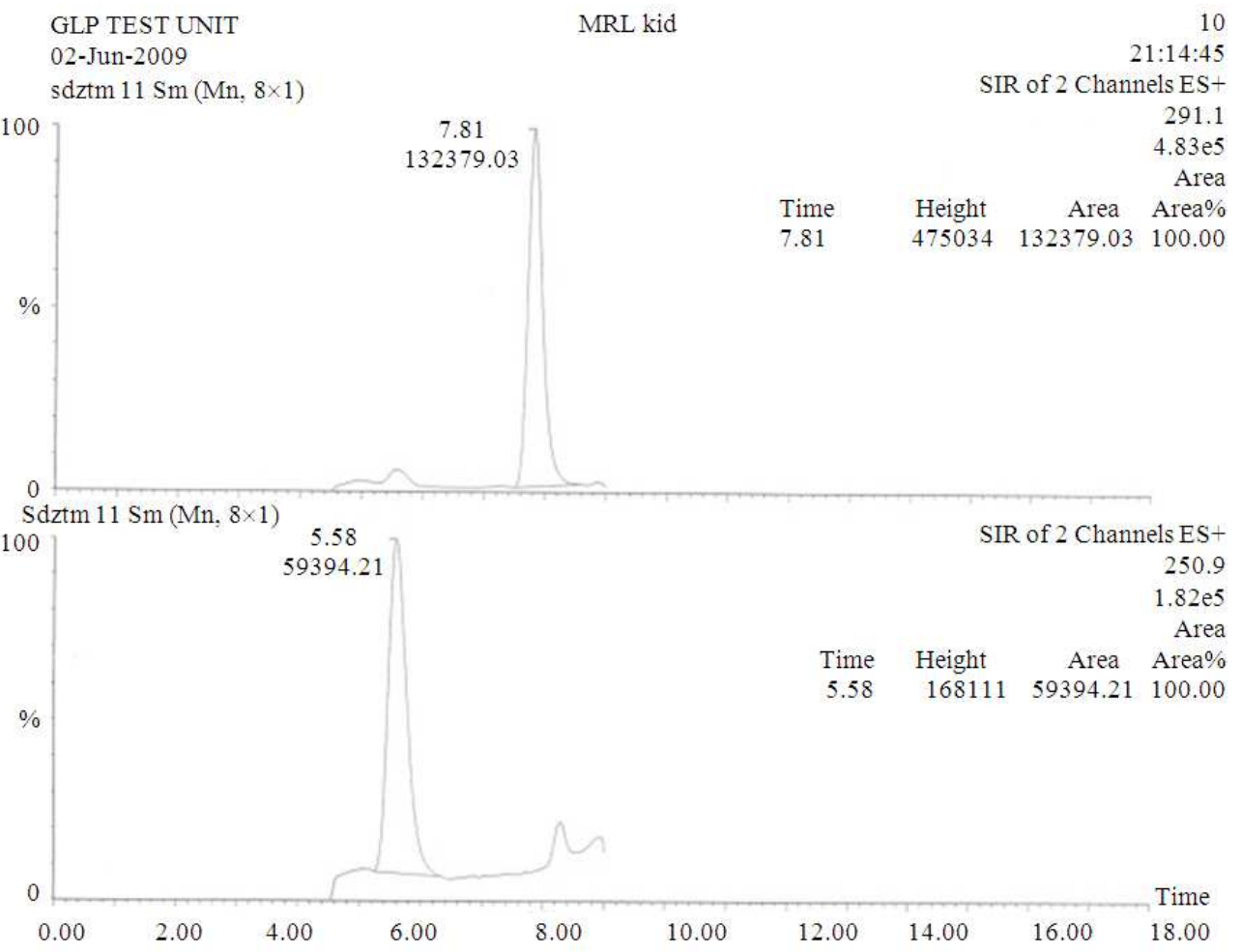

Fig. 1. Chromatogram of a calibration curve sample in kidney (in MRL level)

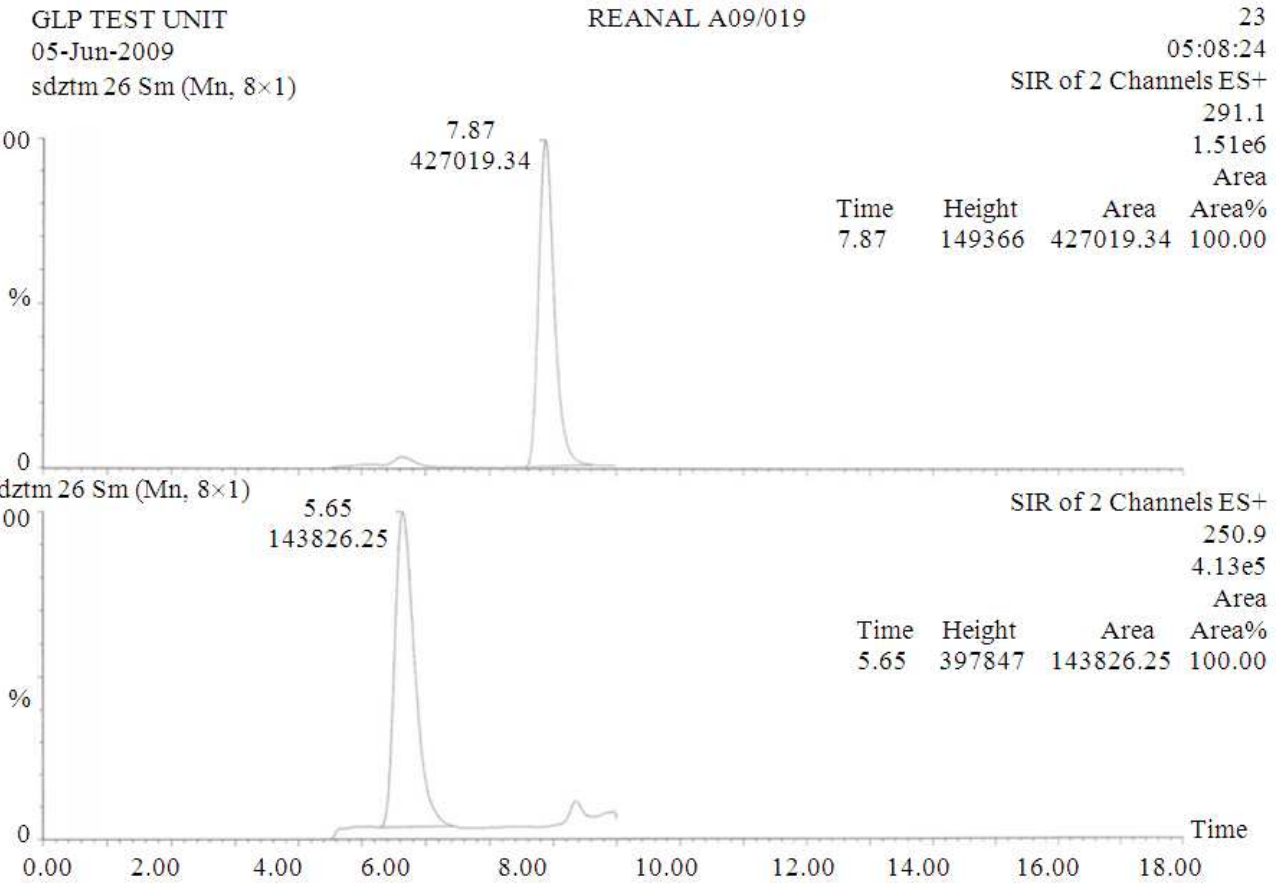

Fig. 2. Chromatogram of a sample (Group A, Kidney) 
After centrifugation the sample was filtered and injected in the LC system for analysis. Each substance was identified by the respective Retention Time $\left(R_{t}\right)$ and mass to charge ratio $(\mathrm{m} / \mathrm{z})$. Ionisation was performed via electron spray source (E.S.I.) operating in the positive ion mode. The ions selected for monitoring were $\mathrm{m} / \mathrm{z}$ 250.9 (protonated molecular ion $\mathrm{MH}^{+}$for SDZ) and $\mathrm{m} / \mathrm{z}$ 291.1 (protonated molecular ion $\mathrm{MH}^{+}$for TMP). Standards for the calibration curve were prepared by spiking drug free tissue samples. Typical chromatographies are shown in Fig. 1-2.

\subsection{Method Validation}

During the validation of the method, the parameters that were evaluated were: Specificity, Linearity and Range, Accuracy, Precision, Limit of Detection (LOD), Limit Of Quantification (LOQ). Validation has been performed according to European Union (EU) legislation, concerning the establishment of maximum residue limits for residues of veterinary medicinal products in foodstuffs of animal origin (EC, 2005) and Commission Decision of 2002/657/EC implementing Council
Directive 96/23/EC, concerning the performance of analytical methods and the interpretation of results (EC, 2002). Method validation was completed successfully and the method was proved to be capable of determining the residues of Sulfadiazine-Trimethoprim in edible tissues of pigs.

\subsection{Statistical Analysis}

Statistical analysis for the calculation of means, standard deviations, coefficients of variation and the linear regression analysis of calibration curves was performed using the Microsoft Excel ${ }^{\circledR}$ software.

\section{RESULTS}

\subsection{General Health Condition}

During the total period of this study no diseases, injuries or adverse events which could have impact on the study were occurred. Mean BW of all animals is summarized in the following Table $\mathbf{1 .}$

Table 1. Mean Body Weight (BW) of tested animals

\begin{tabular}{|c|c|c|c|c|c|c|}
\hline \multirow[b]{2}{*}{$\begin{array}{l}\text { Days after last } \\
\text { administration }\end{array}$} & \multicolumn{3}{|c|}{$\begin{array}{l}\text { Number of } \\
\text { Animals }\end{array}$} & \multicolumn{3}{|l|}{ Mean BW } \\
\hline & Male & Female & $\begin{array}{l}\text { At randomization } \\
(\mathrm{kg})\end{array}$ & $\begin{array}{l}\text { Before } 1^{\text {st }}-2^{\text {nd }}-3^{\text {rd }} \\
\text { Administration }(\mathrm{kg})\end{array}$ & $\begin{array}{l}\text { Before } 4^{\text {th }}-5^{\text {th }} \\
\text { Administration }(\mathrm{kg})\end{array}$ & $\begin{array}{l}\text { Before sacrifice } \\
(\mathrm{kg})\end{array}$ \\
\hline$\overline{1}$ & 4 & 1 & 29.46 & 32.72 & 34.96 & 36.50 \\
\hline 4 & 4 & 1 & 29.66 & 32.80 & 35.06 & 37.86 \\
\hline 7 & 4 & 1 & 29.70 & 32.88 & 35.02 & 38.94 \\
\hline 11 & 4 & 1 & 29.48 & 32.86 & 35.00 & 43.14 \\
\hline For control animals & 1 & 1 & 29.40 & 32.85 & 34.95 & 36.35 \\
\hline
\end{tabular}

Table 2. Summary results for SDZ

\begin{tabular}{llllll}
\hline Group & Animal No. & Muscle $(\mu \mathrm{g} \mathrm{kg})$ & Liver $(\mu \mathrm{g} \mathrm{kg})$ & Kidney $(\mu \mathrm{g} \mathrm{kg})$ & Fat $(\mu \mathrm{g} \mathrm{kg})$ \\
\hline A & 11 & 383.1 & 31.6 & 1079.0 & 480.2 \\
& 12 & 135.7 & NQ & 361.8 & 210.3 \\
& 13 & 148.6 & NQ & 315.2 & 110.7 \\
& 14 & 423.1 & NQ & 1227.1 & 418.3 \\
B & 19 & 549.9 & NQ & 1007.1 & NQ \\
& 15 & ND & NQ & ND & NQ \\
& 16 & ND & NQ & ND & NQ \\
& 17 & ND & ND & ND & ND \\
& 18 & ND & NQ & ND & ND \\
C & 20 & ND & NQ & NQ & NQ \\
& 2 & NQ & NQ & NQ & NQ \\
& 4 & NQ & NQ & ND & NQ \\
& 5 & NQ & NQ & NQ & NQ \\
& 8 & ND & NQ & ND & ND \\
& 10 & ND & NQ & ND & NQ \\
& 1 & ND & NQ & NQ & \\
\hline
\end{tabular}

ND: Not Detected, NQ: Not Quantified 
Table 3. Summary results for TMP

\begin{tabular}{|c|c|c|c|c|c|}
\hline Group & Animal No. & Muscle $(\mu \mathrm{g} \mathrm{kg})$ & Liver $(\mu \mathrm{g} \mathrm{kg})$ & Kidney $(\mu \mathrm{g} \mathrm{kg})$ & Fat $(\mu \mathrm{g} \mathrm{kg})$ \\
\hline \multirow[t]{5}{*}{$\overline{\mathrm{A}}$} & 11 & 98.2 & 216.0 & 785.0 & 47.7 \\
\hline & 12 & 58.8 & 177.7 & 689.7 & 41.2 \\
\hline & 13 & 59.2 & 222.2 & 716.7 & 25.5 \\
\hline & 14 & 35.0 & 110.7 & 504.7 & 14.6 \\
\hline & 19 & 197 & 401.8 & 1291.8 & 73.6 \\
\hline \multirow[t]{5}{*}{ B } & 15 & ND & ND & ND & ND \\
\hline & 16 & ND & ND & ND & ND \\
\hline & 17 & ND & ND & ND & ND \\
\hline & 18 & ND & ND & ND & ND \\
\hline & 20 & ND & ND & NQ & ND \\
\hline \multirow[t]{5}{*}{$\mathrm{C}$} & 2 & ND & ND & NQ & ND \\
\hline & 4 & ND & ND & NQ & ND \\
\hline & 5 & ND & ND & NQ & ND \\
\hline & 8 & ND & ND & NQ & ND \\
\hline & 10 & ND & NQ & 16.6 & ND \\
\hline \multirow[t]{5}{*}{$\mathrm{D}$} & 1 & ND & ND & ND & ND \\
\hline & 3 & ND & ND & NQ & ND \\
\hline & 6 & ND & ND & ND & ND \\
\hline & 7 & ND & ND & ND & ND \\
\hline & 9 & ND & ND & ND & ND \\
\hline
\end{tabular}

ND: Not Detected, NQ: Not Quantified Note: SDZ and TMP were not detected in control animals 21, 22

\subsection{Feed Consumption and Weight Fluctuations}

During the total trial period the feed consumption and weight fluctuations were within normal limits throughout the study.

\subsection{SDZ and TMP Residues}

The results of the analysis in kidney, liver, fat and muscle following administration of OPTIPRIME ${ }^{\circledR} 40 \%$ premix to pigs are presented in Table 2-3. SDZ and TMP were found in quantifiable concentrations in Group A (1 day after oral administration) and in one animal of group C (7 days after oral administration), in kidney. Both substances were found in high concentrations in kidney samples of group A. SDZ and TMP could not be quantified or detected in Groups B, C and D (with the exception of one sample in kidney of Group C).

\section{DISCUSSION}

It is common for veterinarians to use antimicrobials for the treatment or prevention of severe respiratory and enteric diseases. Farmers want to achieve a high level of health status in their farms with the use of cost/effective medications and consumers also want good quality and safe meat without antimicrobial residues, or zoonotic pathogens. Unfortunately, the use of antimicrobials tends to cause bacterial resistance and thus there is a balance between the need to maintain an animal's health, welfare and productivity with the consumer's requirement for uncontaminated meat.

The results of this study indicated that SDZ and TMP were found in quantifiable concentrations only in the kidneys of animals, 1 day after oral administration (Group A), as well as in one animal 7 days after oral administration (Group C). Both substances were found in high concentrations in kidney samples of Group A. SDZ and TMP could not be quantified or detected in Groups $\mathrm{B}, \mathrm{C}$ and $\mathrm{D}$ (with the exception of one sample in kidney of Group C). The above results agree with the findings of Soli et al. (1990), who noticed no unacceptable or antibacterial residues of SDZ or TMP in the kidneys of pigs slaughtered at 5,7 and 10 days after oral administration. However, in this study the number of experimental animal were smaller compared to our experimental design.

Consumer safety needs to be assessed for all pharmacologically active substances which are intended for use in food producing animals in accordance with Council Regulation (EEC) No 2377/90 (EEC, 1990; EC, 2009). Pre-slaughter withdrawal periods have to be established in order to ensure that the residues deplete to permissible concentrations. The withdrawal period is the necessary interval between the last administration of the drug under normal conditions of use and the time when treated animals can be slaughtered for the production of 
safe foodstuffs: The withdrawal period should provide a high degree of assurance both to the producers and the consumers that the concentration of residues in foods derived from treated animals do not exceed the Maximum Residue Levels (MRLs).

The calculation of the withdrawal period of the present study was based on the residue concentrations of both substances. In order to calculate the withdrawal period for OPTIPRIME ${ }^{\circledR} 40 \%$ premix, an alternative approach (Decision Rule) was employed since the EMA application software (EMEA/CVMP/563/02, (2002) WT version 1.4) was used. Based on the concentration results in all tissues and having taken into consideration the Guideline EMEA/CVMP/036/95 (1996) "Approach towards Harmonisation of Withdrawal Periods", a withdrawal period of 5 days is justified for the product OPTIPRIME $^{\circledR} 40 \%$ premix, in pigs.

This finding agrees with the results of a previous study of Garwacki et al. (1996), in which the TMP/SDZ formulation was added to feed in the amount of $6 \mathrm{mg} \mathrm{kg}^{-1}$ BW (TMP) and $30 \mathrm{mg} \mathrm{kg}^{-1} \mathrm{BW}$ (SDZ). These researchers suggested the withdrawal period for such an oral TMP/SDZ not to be less than 5 days. Furthermore, Garwacki et al. (1996) noticed that the administration of oral TMP/SDZ formulations once a day may result in the absolute tissue concentrations of these drugs being too low for antibacterial activity and the withdrawal period for such an oral TMP/SDZ formulation for pigs should not be less than 5 days. However, in this study there were no measures for residues in fat, as in our study.

\section{CONCLUSION}

In conclusion, the results of present study indicated that SDZ and TMP could be quantified or detected only 1 day after oral administration in healthy pigs. Based on the scientific residues guidelines of EMA, a withdrawal period of 5 days are justified for the product OPTIPRIME $^{\circledR} 40 \%$ premix in pigs.

\section{ACKNOWLEDGEMENT}

This study was funded by PROVET S.A. (Aspropyrgos, Attica, GREECE) through the Research Committee of the University of Thessaly (Code no: 3901; Scientific responsible: Dr. G. Christodoulopoulos). The study was conducted according to the procedures described in the protocols and Standard Operating Procedures of GLP Test Unit Laboratory of PROVET S.A. and this report represents a true and accurate record of the results obtained.

\section{REFERENCES}

Akond, M.A., S.M.R. Hassan, S. Alam and M. Shirin, 2009. Antibiotic resistance of escherichia coli isolated from poultry and poultry environment of Bangladesh. Am. J. Environ. Sci., 5: 47-52. DOI: 10.3844/ajessp.2009.47.52

EC, 1999. Commission Regulation. In: Drug Residues in Foods: Pharmacology, Food Safety and Analysis, Botsoglou, N.A. and D.J. Fletouris (Eds.), Macel Dekker, New York.

EC, 2002. Commission decision 2002/657/EC implementing council directive 96/23/EC concerning the performance of analytical methods and the interpretation of results. Off. J. Eur. Commun. L., 125: 10-32.

EC, 2005. European Commission-Volume 8 Notice to Applicants and Note for Guidance-Veterinary Medicinal "Establishment of MRLs for residues of veterinary medicinal products in foodstuffs of animal origin". EudraLex, 8: 1-78.

EEC, 1990. Laying down a Community procedure for the establishment of maximum residue limits of veterinary medicinal products in foodstuffs of animal origin. Off. J. Eur. Comm. L., 224: 1-8.

EMEA/CVMP/036/95, 1996. Note for Guidance: Approach towards harmonisation of withdrawal periods. Canary Wharf, London.

EMEA/CVMP/563/02, 2002. Note for guidance on approach towards harmonisation of withdrawal periods-updated application software. Canary Wharf, London.

Friis, C., N. Gyrd-Hansen, P. Nielsen, L. Notdhoim and F. Rasmussen, 1984a. Pharmacokinetics and metabolism of trimethoprim in neonatal and young pigs. Pediatr. Pharmacol., 4: 231-238. PMID: 6522131

Friis, C., N. Gyrd-Hansen, P. Nielsen, L. Notdhoim and F. Rasmussen, 1984b. Pharmacokinetics and metabolism of sulphadiazine in neonatal and young pigs. Acta Pharmacol. et Toxicol., 54: 321-326. PMID: 6464778

Garwacki, S., J. Lewicki, M. Wiechetek, S. Grys and J. Rutkowski et al., 1996. A study of the pharmacokinetics and tissue residues of an oral trimethoprim/sulphadiazine formulation in healthy pigs. J. Vet. Pharmacol. Ther., 19: 423-430. PMID: 8971670

Guise, H.J., R.H. Penny and D.J. Petherick, 1986. Streptococcal meningitis in pigs: Field trial to study the prophylactic effect of trimethoprim/sulphadiazine medication in feed. Vet. Rec., 119: 395-400. PMID: 3798680 
Kandimalla, V.B., N. Kandimalla, K. Hruska and M. Franek, 2007. Detection of sulfamethazine in water, milk and pig manure by dipstick immunoassay. Vet. Med., 52: 445-450.

KuKanich, B., R. Gehring, A.I. Webb, A.L. Craigmill and J.E. Riviere, 2005. Effect of formulation and route of administration on tissue residues and withdrawal times. J. Am. Vet. Med. Assoc., 227: 1574-1577. PMID: 16313034

Long, A.R., L.C. Hsieh, M.S. Malbrough, C.R. Short and S.A. Barker, 1990. Multiresidue method for the determination of sulfonamides in pork tissue. J. Agric. Food Chem., 38: 423-426. DOI: 10.1021/jf00092a018

Lu, G., 1986. Pharmacokinetic studies of sulfadoxine and sulfadoxine-trimethoprim combination in swine. Chinese J. Anim. Vet. Sci.

Luther, H., 1979. The pharmacokinetics of sulfadiazine in cattle, sheep and swine. Diss. Abstr. Intern., B, 39: 5789-5790.

McCaughey, W.J., C.T. Eilliot, J.N. Campbell, W.J. Blanchflower and D.A. Rice, 1990. Tissue residues in pigs fed on meal contaminated with sulphadimidine during mixing. Ir. Vet. J., 43: 127-130.

Nielsen, P. and N., Gyrd-Hansen 1994. Oral bioavailability of sulphadiazine and trimethoprim in fed and fasted pigs. Res. Vet. Sci., 56: 48-52. PMID: 8146453

Pastor-Navarro, N., A. Maquieira and R. Puchades, 2009. Review on immunoanalytical determination of tetracycline and sulfonamide residues in edible products. Anal. Bioanal. Chem., 395: 907-920. DOI: 10.1007/s00216-009-2901-y

Pastor-Navarro, N., C.G. Bover, A. Maquieira, R. Puchades, 2004. Specific polyclonal-based immunoassays for sulfathiazole. Anal. Bioanal. Chem., 379: 1088-1099. PMID: 15221195
Randall, L.P., S.W. Cooles, M.K. Osborn, Piddock LJ and M.J. Woodward, 2004. Antibiotic resistance genes, integrons and multiple antibiotic resistance in thirty-five serotypes of Salmonella enterica isolated from humans and animals in the UK. J. Antimicrob. Chemother., 53: 208-216. DOI: 10.1093/jac/dkh070

Rokka, M., S. Eerola, U. Perttila, L. Rossow and E. Venalainen et al., 2005. The residue levels of narasin in eggs of laying hens fed with unmedicated and medicated feed. Mol. Nutr. Food Res., 49: 3842. PMID: 15538711

Schwarz, S. and E. Chaslus-Dancla, 2001. Use of antimicrobials in veterinary medicine and mechanisms of resistance. Vet. Res., 32: 201-225. PMID: 11432414

Soli, N.E., T. Framstad, E. Skjerve, S. Sohlberg and S.A. Odegaard, 1990. A comparison of some of the pharmacokinetic parameters of three commercial sulphadiazine/trimethoprim combined preparations given orally to pigs. Vet. Res. Commun., 14: 403410. PMID: 2247946

Wang, J., A. Sonnerborg, A. Rane, F. Josephson and S. Lundgren et al., 2006. Identification of a novel specific CYP2B6 allele in Africans causing impaired metabolism of the HIV drug efavirenz. Pharmacogenet Genomics, 16: 191-8. PMID: 16495778

EC, 2009. Council Regulation (EC) No 470/2009 of 6 May 2009 laying down Community procedures for the establishment of residue limits of pharmacologically active subtances in foodstuffs of animal origin, repealing Council Regulation (EEC) No 2377/90. Off. J. Eur. Comm. L., 152: 11-22. 